UC. 4

Issued: July i377

\title{
Evaluation of the LASL Automated Spectrophotometer for Uranium Determination at Submilligram Levels
}

\author{
R. M. Hollen \\ D. D. Jackson \\ J. E. Rein
}




\title{
EVALUATION OF THE LASL AUTOMATED \\ SPECTROPHOTOMETER FOR URANIUM DETERMINATION AT SUBMILLIGRAM LEVELS
}

by

\author{
R. M. Hollen, D. D. Jackson, and J. E. Rein
}

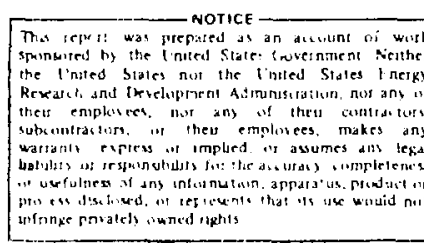

\begin{abstract}

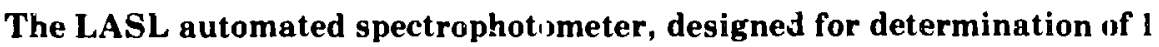
to $14 \mathrm{mg}$ of uranium and 0.5 to $14 \mathrm{mg}$ of plutonium, has been evaluated for determination of lower levels of uranium to $0.12 \mathrm{mg}$. The essentially linear response of absorbance is maintained and the standard deviation for a s.ingle measurement is constant at about $0.013 \mathrm{mg}$ of uranium, corresponding to a maximum uncertainty of about $10 \%$ at the $0.12-\mathrm{mg}$ limit. 'The instrument was applied to the analysis of a series of low-levelconcentration, $0.07-$ to $0.8-\mathrm{mg} / \mathrm{m} \ell$ uranium samples. The results were not statistically different from those obtained by a manual spectrophotometric method.
\end{abstract}

\section{INTRODUCTION}

The Los Alamos Scientific Laboratory (I.ASL) automated spectrophotometer was developed in 1975 for the determination of uranium and plutonium. A detailed report' describes the mechanical and electrical features, the hardware and softrare of the microcomputer control system. instrument operation, chemical procedures for in. strument calibration and analysis of samples, and data showing accuracy and precision capability for determining 1 to $12 \mathrm{mg}$ of uranium. The instrument was designed primarily for the analysis of scrap-type materials, usually characterized by low uranium and/or plutonium contents, high contents of many impurity elements, and heterogeneity. The design emphasized high specificity, moderate precision capability of 0.010 to $0.020 \mathrm{mg}$ standard deviation, a throughput rate of $5 \mathrm{~min}$ per sample, and mechanical simplicity.
The chemical procedure used in the instrument involves the extraction of tetrapropylammonium uranyl and plutonyi trinitrate complexes into 2nit ropropane and measurement of the optical absorbances in the organic phase at unique peak wavelengths. The instrument features a turntable that rotates as many as 24 samples in tubes made from precision-bore tubing to a series of stations for the sequential chemical operations and ebsorbance measurements. All operations, including the absorbance measurement, are done without transfer of the sample. Output is a paper tape printout of three series of numbers, one proportional to the absorbance of the uranilim or plutonium complex, a second designating turntable position for sample identification, and the third designating whether uranium or plutonium was determined.

The analyst delivers the sample to a tube as a volume or weight aliquot and the tube is transferred 
to the turntable. The maximum sample volume is $0.5 \mathrm{ml}$. Larger volumes of samples containing low concentrations of uranium or plutonium may be evaporated in the tubes before transfer to the instrumeni. The evaporation of samples in tubes is not labur-consuming; howevar, there can be a technical disadvantage. For samples containing high amounts (f) impurities relative to uranium or plutonium, the residue can be difficult to dissolve completely in 0.5 $\mathrm{m} \ell$ of acid. Undissolved residue can retain small amounts of uranium or plutonium.

T'o extend the applicability of the automated spectrophotometer, we are currently adapting another uranium spectrophotometric method that has sensitivity to low microgram levels. ${ }^{2}$ Meanwhile, the need 10 analyze samples from various uranium recovery processes in which the concentrations of uranium generally are within the range of 0.05 to 1 ng $/ m \ell$ prompted an evaluation of the instrument, without chemical or instrumental modifications. for luwer level uranium analyses. This evaluation consisted of a 15-day processing of standard solutions (ontaining 0.12 to $1.5 \mathrm{mg}$ of uranium as well as the analysis of 32 uranium samples from a recovery process. The 32 samples also were analyzed by an expcrienced analyst who used a well-proven, manual spectrophotometric merhod. ${ }^{3}$

\section{I1. INSTRUMENT EVALUATION FOR SUB- MILIIGRAM UKANIUM LEVELS}

(I) each of 15 days over an elapsed time of almost a month, six weight aliquots at each of four levels of 1).12. 10.27, 0.56, and $1.5 \mathrm{mg}$ of uranium were pricessed using the automated spectrophotometer. Alur processed each day were four blank silutions-ta total of 420 measurements. The aljquots were taken from solutions that had been prepared by nitric acid dissolution of a well. characterized, $>99.9 \%$ pure uranium metal.

Ising all the data. a calibration equation was computed by least squares fitting for the four-digit output number that is proportional to absorbance, in turn proportional to the milligrams of uranium. 'The equation, a second-order polynomial, was almost linear, as was the equation obtcined previnusly for the range of 1 to $14 \mathrm{mg}$ of uranium. We used this equation to calculate the milligrams of uranium eorresponding to each output number. The variance of the 90 values at each of the four levels of $0.12,0.27,0.56$, and $1.5 \mathrm{mg}$ uranium was computed. Bartlett's test. for comparison of more than two variances showed no difference, indicating a constant precision over the range. The pooled standard deviation (for a single measurement) was $0.013 \mathrm{mg}$ of uranium. The corresponding relative standard deviations ranged from $10.4 \%$ at $0.12 \mathrm{mg}$ of uranium to $0.87 \%$ at $1.5 \mathrm{mg}$ of uranium.

Ar analysis of variance of the data indicated a difference at the $95 \%$ significance level for betweenday measurements relative to the withiii-day measurements. Although significant, the difference is small. The averages of the deviations of the 24 results for the day of highest and the day of lowest results, relative to the grand average of results for all 15-day data, were $+0.021 \mathrm{mg}$ and $-0.024 \mathrm{mg}$, respectively. This effect can be decreased by adjusting the calibration on the basis of results oh. tained for concurrently analyzed standards. For the data obtained in this evaluation, an adjustment based on daily processing of two standards each at the upper and lower ends of the range would decrease the above obtained averages of the devia tions to +0.004 and $-0.001 \mathrm{mg}$.

\section{ANALYSIS OF LOW-CONCENTRATION URANIUM SAMPLES}

A series of 32 routine samples, containing 0.0 ? to $0.8 \mathrm{mg} / \mathrm{m} \ell$ uranium concentrations, was arialyzed with the automated spectrophotoneter as we!l as by a skilled analyst using a well-proven manual spec. trophotometric method. ${ }^{3}$ The samples were solutions from a stage in a uranium recovery process. They contained significant quantities of various $\mathrm{im}$. purities and some had fine suspended material. About half were in a nitric acid medium and haif were in sulfuric acid.

The maximum sample volume is $0.5 \mathrm{~m} \ell$. Half of the samples contained $<0.3 \mathrm{mg} / \mathrm{m} \ell$ of uranium. To attain more reliable results, we analyzec $10 \cdot \mathrm{m} \ell$ volumes having a uranium range of $0.7108 \mathrm{mg}$. Two sequential $5 \cdot \mathrm{m} \ell$ volumes were evaporated in the tubes. A $0.5-\mathrm{m} \ell$ volume of $8 M \mathrm{HNO}_{3}$ was added to dissolve the residue and the tubes were transferred to the instrument. Juplicates were analyzed.

The instrument was calilirated just before sample analysis by processing a series of $2 R$ weight aliquots 
of standard solutions, prepared with $>99.9 \%$ pure uranium metal, over the range of 0.25 to $14 \mathrm{mg}$ of uranium. A regression line was fitted to the data by a least squares computation. As in the past, ${ }^{1}$ a sccond-order polynomial, although almost a straight line, fitted the data better. During sample analysis. standards were processed daily to confirm satisfactory operation. The calibratirn was not adjusted.

Two types of statistical tests, " $t$ " and WilcoxonSigned Ranks, were applied to compare the results obtained from use of the automated spectrophotometer to those obtained by the manual spectrophotometric method (Table I). Neither test showed a significant difference. The algebraic grand average difference was $0.0017 \mathrm{mg}$ of uranium. 'The grand average difference calculated without regard to sign was only $0.0037 \mathrm{mg}$ of uranium.

The standard deviation for a single measurement of the automated spectrophotometer results, computed from the duplicate analysis results, was 0.039 $\mathrm{mg}$ of uranium, corresponding to $6 \%$ and $0.5 \%$ at the 0.7-mg and 8-mg extremes.

\section{ACKNOWLEDGMENT}

Ludie Pulliam performed the manual spectrophotometric analysis.

\section{RFFERENCES}

1. D. D. Jackson, D. J. Hodgkins, R. M. Hollen, and J. E. Rein, "Automated Spectrophotometer for P'utonium and Uranium Determination," Los Alamos Scientific Laboratory report LA-6091 (February 1976).

2. G. R. Waterbury, Comp., "Analytical Methods for Fissionable Materials in the Nuclear Fuel Cycle. July 1, 1975 to September 30, 1976," Los Alamos Scientific Laboratory report LA-6577.PR (Decem. ber 1976).

3. A. L. Henicksman. "The Spectrophotometric Determination of $i_{i}$ anium." Los Alamos Scientific Laboratory report L.A-1394 (March 1952).
TABLE I

\section{RESULTS OF URANIUM SAMPLES ANALYZED BY THE AU'TOMATED SPECTROPHOTOMETER AND A MANUAL SPECTROPHOTOMETRIC METHOD}

\begin{tabular}{|c|c|c|c|}
\hline Sarıple & $\begin{array}{l}\text { Automated } \\
\text { Spectro- } \\
\text { photometer } \\
(\mathbf{m g} / \mathbf{m} \ell)^{\mathbf{a}}\end{array}$ & $\begin{array}{c}\text { Manuai } \\
\text { Spectro- } \\
\text { photometric } \\
\text { Method } \\
\text { (mg/m:) }\end{array}$ & Difference \\
\hline 1 & 0.380 & 0.374 & +0.006 \\
\hline 2 & 0.374 & 0.373 & +0.001 \\
\hline 3 & 0.262 & 0.251 & +0.011 \\
\hline 4 & 0.253 & 0.251 & +0.002 \\
\hline 5 & 0.348 & 0.352 & -0.004 \\
\hline 6 & 0.354 & 0.352 & +0.002 \\
\hline 7 & 0.456 & 0.160 & -0.004 \\
\hline 8 & 0.459 & $\left.0.4 e^{n}\right)$ & -0.001 \\
\hline 9 & 0.626 & 0.625 & +0.001 \\
\hline 10 & 0.627 & 0.625 & +0.002 \\
\hline 11 & 0.702 & 0.707 & -0.005 \\
\hline 12 & 0.711 & 0.707 & +0.004 \\
\hline 13 & 0.385 & 0.385 & 0.000 \\
\hline 14 & 0.386 & 0.387 & -0.001 \\
\hline 15 & 0.232 & 0.232 & 0.000 \\
\hline 16 & 0.233 & 0.232 & 40.001 \\
\hline 17 & 0.145 & 0.149 & -0.004 \\
\hline 18 & 0.147 & 0.149 & -0.002 \\
\hline 19 & 0.050 & 0.051 & -0.001 \\
\hline 20 & 0.048 & 0.051 & -0.003 \\
\hline 21 & 0.237 & 0.241 & -0.004 \\
\hline 22 & 0.237 & 0.241 & -0.004 \\
\hline 23 & 0.126 & 0.125 & +0.001 \\
\hline 24 & 0.125 & 0.125 & 0.000 \\
\hline 25 & 0.066 & 0.070 & -0.004 \\
\hline 26 & 0.066 & 0.068 & -0.002 \\
\hline 27 & 0.111 & 0.114 & -0.003 \\
\hline 28 & 0.116 & 0.114 & +0.002 \\
\hline 29 & 0.770 & 0.787 & -0.017 \\
\hline 30 & 0.766 & 0.768 & -0.022 \\
\hline 31 & 0.434 & 0.436 & -0.002 \\
\hline 32 & 0.432 & 0.436 & -0.004 \\
\hline
\end{tabular}

